4. Walshe C, Todd C, Caress A-L, Chew-Graham C. Judgements about fellow professionals and the management of patients receiving palliative care in primary care: a qualitative study. Br J Gen Pract 2008; 58(549): 264-272.

5. Craddock D, O'Halloran C, Borthwick A, McPhearson $\mathrm{K}$. Interprofessional education in health and social care: fashion or informed practice? Learn Health Soc Care 2006; 5(4): 220-242.

6 Thomas P, Graver L. The Liverpool intervention to promote teamwork in general practice: an action research approach. In: Pearson P, Spencer J (eds). Promoting teamwork in primary care. A research-based approach. London: Arnold, 1997: 174-191.

7. Bryar R. 'Since the centre started I am a different woman.' Report of a WHO fellowship visit to the Netherlands. Teamcare Valleys Completion Report. Cardiff: Teamcare Valleys, 1992.

8. West M, Poulton B. Primary health care teams: in a league of their own. In: Pearson, P, Spencer J (eds). Promoting teamwork in primary care. A research-based approach. London: Arnold, 1997: 12-26.

9. Thomas P. Integrating primary health care, leading managing, facilitating. Abingdon: Radcliffe Medical
Press, 2006.

10. Bryar R, Bytheway B. Changing primary health care. The Teamcare Valleys Experience. Oxford: Blackwell Science, 1996.

11. Meads G, Ashcroft J. The case for interprofessional collaboration in health and social care. Oxford: Blackwell Publishing, 2005.

12. Silverman D. The theory of organisations. London: Heinemann, 1970.

13. Freeth D, Hammick M, Barr H, Koppel I, Reeves S Effective interprofessional education: development delivery and evaluation. Oxford: Blackwell Science, 2005.

14. Addington-Hall J, Shipman C, Burt J, et al. Evaluation of the education and support programme for district and community nurses in the principles and practice of palliative care. London: King's College, 2006.

15. Pearson P, Steven A, Dickinson C. Learning together in practice. A final report on IPE for modernising health and social care. Newcastle: University of Newcastle, 2006.

16. Nursing and Midwifery Council. Review of preregistration nurse education. http://www.nmc-uk.org (accessed 6 Mar 2008).
17. Health Care Innovation Unit. Common learning. http://www.commonlearning.net/ (accessed $6 \mathrm{Ma}$ 2008)

18. Kendrick T, Hilton S. Primary care: opportunities and threats. Broader teamwork in primary care. BMJ 1997; 314(7081): 672-675.

DOI: 10.3399/bjgp08X279733

\section{ADDRESS FOR CORRESPONDENCE:}

\section{Rosamund Bryar}

Professor of Community and Primary

Care Nursing, Public Health, Primary Care and Food Policy Department,

City Community and Health Sciences,

City University, 20 Bartholomew Close,

London EC1A 7QN.

E-mail:R.M.Bryar@city.ac.uk

\title{
The Tooke report: good news for general practice?
}

During the 1960s - when it was still possible to enter general practice immediately after completion of the preregistration house officer year - the Royal College of General Practitioners (RCGP) sought to improve standards of care for patients by introducing vocational training for general practice.

Although the RCGP proposed a 5-year period of vocational training at that time, resource constraints within the NHS meant that only 3-year programmes could be developed, and with only 1 year in general practice itself.

Initially voluntary, there was no requirement to undertake any training until 1978 when primary legislation was introduced making it mandatory to complete 12 months in general practice. Subsequent changes to the legislation in 1983 required completion of 3 years' training to become a principal and in 1990 required completion of training to work in any capacity within general practice. Although the majority of trainees took the MRCGP examination, there was no requirement to demonstrate satisfactory completion of training until 1996 when summative assessment became mandatory.

The changes brought about by the Postgraduate Medical Education and Training Board (PMETB) gave us the opportunity to develop specialty training for general practice, ensuring that doctors have the competences necessary to provide high standards of medical care for patients.

The PMETB set explicit standards for both the training curriculum and the assessment of completion of training that needed to be met by all medical specialties including general practice. The curriculum for general practice ${ }^{1}$ was given unconditional approval by PMETB. Although the curriculum is competencerather than time-based, the PMETB approval panel rightly questioned the RCGP closely on the challenges of completing training in such a complex discipline in only 3 years.

Although general practice is the most widely challenging field of medical practice, it has the shortest period of specialty training. The nature of practice and the complexity of clinical care delivered by GPs have changed dramatically since the inception of GP training schemes - yet the duration of training has not increased to take account of this.

This is reflected in various documents from all four Departments of Health and given particular emphasis in Modernising Medical Careers: The Next Steps ${ }^{2}$ (MMC). This key document highlights that: 'The advent of Modernising Medical Careers offers the opportunity to develop a new and better approach to GP training ... which is a significant improvement over existing arrangements ... GP training will increasingly be based in and from general practice'.

This was further highlighted in Sir John Tooke's review ${ }^{3}$ which concluded that: '... although a deeply damaging episode for British medicine, from this experience must come a recommitment to optimal standards of postgraduate medical education and training.' One of the key recommendations made by Tooke is that ' ... the length of training in general practice should be extended to 5 years'. This recommendation has attracted widespread support from across the profession, not just from general practice. 


\section{TOOKE'S PROPOSALS FOR SPECIALTY TRAINING}

The UK competitive selection process for general practice was one of the few components of MMC that was acknowledged by Tooke to be a success. The selection process is a good example of how deaneries and the RCGP have worked together over the years to develop a system that has become accepted across the country and is now being copied by other specialties.

In future, the majority of trainees would continue to be selected through that process to enter 5-year training programmes, but there will also be opportunities for some trainees to move from other specialties into GP training at the end of the third year of core training.

The RCGP wishes to support the call for flexibility in the design of training programmes and acknowledges that trainees undertaking core training programmes in other specialties may wish to move across to specialty training for general practice. It cannot be assumed that such trainees will have the necessary competences or abilities to enter general practice training without an assessment of these. (Indeed, there is some evidence from earlier training programmes that trainees transferring from other specialties find it quite difficult to adapt to general practice, and they often require longer periods of training than those who have chosen general practice from the outset.)

Trainees would be subject to deanery review and the nMRCGP defined assessments throughout their training programme. Successful completion of training would be marked by the award of a Certificate of Completion of Training allowing entry onto the General Medical Council's GP Register.

The final year of specialty training would see experienced specialty registrars nearing completion of a structured and integrated training programme specifically designed to deliver GPs for the provision of modern primary care.

Although the RCGP would have a role in the approval of programmes of training (to meet the obligations expected of it by the PMETB), the local management and implementation of run-through, core, and specialty training programmes should rest with the directors of postgraduate general practice education.

\section{THE FUTURE: GPS GROUNDED IN CLINICAL EXCELLENCE}

The curriculum fits in well with the development of the discipline of general practice in Europe and across the world. These developments are grounded in the belief that we should aspire to clinical excellence in general practice.

When we began work on the curriculum, we performed an extensive review of the world's literature and dissected curriculum models developed and applied elsewhere in the world. These included curricula from Australia, Canada, Denmark, Eire, the Netherlands, Norway, Portugal, Spain, and the US. The final curriculum document draws heavily on the framework was that devised by the World Organization of Family Doctors (WONCA Europe) because of its international applicability and its acceptance by the national colleges and associations of family medicine in 30 countries in Europe. Moreover, as the UK is subject to EU Directive 93/16/EEC, which promotes free movement of doctors through mutual recognition of training, it was argued that it would be desirable to use a framework familiar to other nations in the Union.

Tooke concludes his report by asserting that '... an aspiration to clinical excellence in the interests of the health of the population must be paramount'. In making this statement, Tooke reaffirms the longheld view of the RCGP which is clearly demonstrated in the learning outcomes described in the curriculum.

The RCGP strongly supports the implementation of Recommendation 45 of the Tooke review that ' ... the length of training in general practice should be extended to 5 years'.

We are delighted that Scotland is leading the way with a significant number of trainees offered a 4-year training

programme starting in August this year. We very much hope England and other parts of the UK will follow soon.

We believe that general practice is an academic discipline but that it requires more investment to create the general practice teachers and researchers of the future.

While the Walport initiative, which in 2007 created a small number of academic fellows and lecturers in general practice, was a good start, the numbers compared to hospital-based specialties remains woeful. There must be more academic training programmes established in all parts of the UK. We would like to work with the Society for Academic Primary Care and the National Primary Care Research and Development Centre to develop these programmes.

We have an unparalleled opportunity to develop specialty training for general practice to ensure that it produces GPs with the skills to deliver the quality of care that patients need and deserve - and in ensuring that family medicine is at the core of training for all our doctors of the future.

\section{Steve Field,}

Professor, Chairman of the Royal College of General Practitioners, London

\section{REFERENCES}

1. RCGP Training Curriculum for General Practice. RCGP 2007 http://www.rcgp-curriculum.org.uk (accessed 17 Mar 2008).

2. Four UK Health Departments. Modernising medical careers: the next steps. The future shape of foundation, specialist and general practice training programmes. Leeds: Department of Health, 2004

3. MMC Inquiry. Aspiring to excellence: final report of the independent inquiry into modernising medical careers. Led by Sir John Tooke. MMC Inquiry, 2008.

DOI: 10.3399/bjgp08X279742

ADDRESS FOR CORRESPONDENCE:

Steve Field,

Professor, Chairman of the Royal College of General Practitioners, London.

Email: chairman@rcgp.org.uk

Discuss these editorials. Contribute and read comments about these editorials on the Discussion Forum: http://www.rcgp.org.uk/bjgp-discuss 